\title{
Participation in physical and social activities among home-dwelling persons with dementia - experiences of next of kin
}

This article was published in the following Dove Press journal:

Psychology Research and Behavior Management

25 June 2013

Number of times this article has been viewed

\author{
Ulrika Söderhamn' \\ Bjørg Landmark ${ }^{2,3}$ \\ Sissel Eriksen ${ }^{2}$ \\ Olle Söderhamn' \\ 'Center for Caring Research - \\ Southern Norway, Faculty of Health \\ and Sport Sciences, University \\ of Agder, Grimstad, ${ }^{2}$ Institute \\ of Research and Development \\ for Nursing and Care Services, \\ Municipality of Drammen, Drammen, \\ ${ }^{3}$ Faculty of Health Sciences, Buskerud \\ University College, Drammen, Norway
}

Correspondence: Ulrika Söderhamn Center for Caring Research - Southern Norway, Faculty of Health and Sport Sciences, University of Agder, PO Box 599, NO-4898 Grimstad, Norway

Tel +4737233789

Email ulrika.soderhamn@uia.no
Introduction: To be next of kin to a home-dwelling person with dementia is known to be a heavy burden, especially early in the process. Studies have revealed a need for information and support during the disease process. Likewise, there is support for the positive impacts of physical and social activities for wellbeing in home-dwelling people with dementia. It is important to obtain experiences from next of kin whose spouses or parents participate in such physical and social activities.

Aim: The aim of this study was to elucidate the experiences of next of kin to home-dwelling persons in an early stage of dementia who had an opportunity to participate in organized physical and social activities.

Method: The study has a qualitative design. Focus group interviews were conducted with ten next of kin to home-dwelling dementia sufferers, who participated in physical and social activities in an activity center. The interview texts were analyzed using qualitative content analysis.

Findings: In the analysis, two categories emerged: "a break in the everyday" and "being attended and cared about." Two sub-categories identified in each of the two main categories were: "need of relief" and "meaningful activities," and "being confirmed" and "sharing experiences and getting advice and help," respectively. These categories were interpreted in an overall theme: "contentment with adapted activities and group meetings provided with a person-centered approach."

Conclusion: Adapted physical and social activities led by highly qualified personnel can provide needed relief and support to the next of kin, and meaningful activities to the dementia sufferers. However, it is crucial that the personnel provide person-centered care and are able to meet the needs of the dementia sufferers and their next of kin, to help to give them a new everyday life.

Keywords: activity center, content analysis, parent, qualitative design, spouse

\section{Introduction}

To be next of kin to a home-dwelling person with dementia is known to be a heavy burden, especially early in the disease process. ${ }^{1}$ This can be explained by the fact that there is no cure for dementia ${ }^{2}$ and the knowledge that the disease is going to get worse, both of which give a feeling of fear to those with dementia ${ }^{3}$ and to their next of kin. Because of uncertainty about the prognosis and the future, ${ }^{4}$ next of kin need information and support during the disease process. However, such support has been shown to be inadequate. ${ }^{4}$

Spouses especially, have reported feelings of depression and social isolation during the disease process. The feeling of isolation can occur due to reduced possibilities of talking to the person with dementia on the same premises as earlier on. The network 
can be limited, because friends with a lack of knowledge about the disease sometimes withdraw due to difficulties in handling the situation. ${ }^{4}$ To be a family caregiver, for example a spouse, can cause feelings of loneliness if there is no possibility of respite in the form of help or support from other family members or friends. ${ }^{5}$ Moreover, informal caregivers can feel that they are obliged to provide care, even if this is of their own free will, and be disappointed because this help can be taken for granted by the health care system. ${ }^{6}$

In Norway, it is a general policy that everyone should feel confident that their care needs will be secured and that health care services will be provided, as far as it is possible, according to the individuals' wishes and needs. However, it is also well known that many next of kin to home-dwelling persons with dementia in Norway take responsibility for the care without help from the health care system and, therefore, are in great need of information, guidance, and advisory services. ${ }^{7}$ The fact that next of kin as caregivers have a need for information and support about dementia disease is supported in studies. ${ }^{4-6,8}$ Likewise, there is support for the positive impact of physical ${ }^{9}$ and social activities ${ }^{10}$ for the perception of wellbeing in home-dwelling people with dementia. There has been a great focus on dementia sufferers in Norway, and more research that can facilitate the provision of an active and social life is requested. ${ }^{7}$ As part of this commitment, it is important to obtain experiences from next of kin, whose spouses or parents participate in such physical and social activities.

\section{Aim}

The aim of this study was to elucidate the experiences of next of kin to home-dwelling persons in an early stage of dementia who had an opportunity to participate in organized physical and social activities.

\section{Methods}

\section{Design and setting}

The study has a qualitative design with focus group interviews performed during 2012. Data were collected from next of kin to home-dwelling dementia sufferers living in a city in southern Norway. The dementia sufferers participated in organized activities in an activity center that offered physical and social activities in the daytime, 4 days each week, for home-dwelling persons with an early stage of dementia. Examples of activities offered in the center were walking, sports, games, talking and singing, drinking coffee, and eating meals together. One day a week there was an opportunity for the next of kin to participate in groups led by professionals, who were nurses and specialists in dementia care. In addition, volunteers participated in the activities and the meal preparation for the dementia sufferers.

The next of kin and the persons with dementia had been introduced to the opportunity of using the activity center by the geriatrician, when the dementia diagnosis was made, or by the public health nurse or a friend. Participation in the activities was free, and the persons with dementia could choose the activities in which they wished to participate. How often the center was frequented varied. Most participated regularly 2-3 days each week.

\section{Study group}

Next of kin to individuals in an early stage of dementia who frequented the activity center were informed about the study by the professionals in the center, in connection with an information meeting and group meetings for next of kin. From 100 next of kin, approximately 25 participated in the information sessions about the study. Twelve next of kin reported their interest in participating and were, thereafter, contacted by telephone by two of the authors for additional information about the study. One next of kin had no opportunity to participate in an interview due to other duties, while eleven agreed to participate. Written information about the study and a form for signed consent was sent by mail. Ten persons met the appointments for the interviews and gave their written consent to participate. Thus, the study group consisted of ten next of kin, seven women and three men. Eight of the informants had a relationship as a spouse and two as a child to the persons with dementia. Characteristics of the informants are displayed in Table 1.

\section{Interviews}

Two focus group interviews with five next of kin, respectively, were conducted. Focus group interviews were chosen

Table I Characteristics of the informants

\begin{tabular}{llll}
\hline Informant & $\begin{array}{l}\text { Age } \\
\text { (years) }\end{array}$ & $\begin{array}{l}\text { Relationship to the } \\
\text { dementia sufferer }\end{array}$ & $\begin{array}{l}\text { Duties outside } \\
\text { the home }\end{array}$ \\
\hline Informant A & 74 & Wife & Yes \\
Informant B & 72 & Husband & No \\
Informant C & 57 & Wife & Yes \\
Informant D & 69 & Wife & Partly \\
Informant E & 70 & Wife & No \\
Informant F & 83 & Husband & Yes \\
Informant G & 70 & Wife & No \\
Informant H & 36 & Daughter & Yes \\
Informant I & 55 & Son & Yes \\
Informant J & 73 & Wife & No \\
\hline
\end{tabular}


to collect data because they have the advantage of generating a dialogue ${ }^{11}$ between the informants. The interviews were performed in the activity center and were conducted by one of the authors as a moderator, who guided the dialogue according to topics in a semi-structured interview guide. Another author participated as an observer. The topics used in the interview guide were challenges in everyday life, experiences from the activities in the center and organization of the activities, and thoughts about the future. The interviews lasted up to 2 hours and were transcribed verbatim.

\section{Data analysis}

The transcribed interview text was analyzed using qualitative content analysis ${ }^{12}$ according to the following steps: (1) The text was read to obtain a sense of the whole, (2) The text was broken down into "meaning units", ie, in sentences or paragraphs that according to their content were similar, (3) These meaning units were condensed, (4) The condensed units were abstracted and labeled with a code, (5) The codes were compared according to differences and similarities and sorted into four sub-categories ("need of relief," "meaningful activities," "being confirmed," and "sharing experiences and getting advice and help") and two broader categories ("a break in the everyday" and "being attended and cared about"). Steps 1 to 5 constituted a manifest content analysis. (6) The final step constituted a latent content analysis, where the underlying meaning, ie, the latent content of the categories, was formulated in an overall theme ("contentment with adapted activities and group meetings provided with a personcentered approach"). Examples of codes, the sub-categories, the categories, and the theme are displayed in Table 2.

\section{Ethics}

The intentions of the Declaration of Helsinki ${ }^{13}$ and ethical standard principles ${ }^{14}$ were followed when designing and performing the study. As part of a larger project on development of home care services for people with dementia, the study was approved by the Regional Committee for Medical Research Ethics in southern Norway (REK Sør-Øst C, 2010/71942).

\section{Findings}

The findings are presented in two categories and two subcategories, respectively, and also by an overall theme.

\section{A break in the everyday Need of relief}

To be a spouse or a child of a person with dementia was experienced as very challenging. The dementia disease was experienced as being very tough, because they lost their loved one step by step during a long period. The disease offered different challenges related to the degree of dementia. Some of the dementia sufferers could perform domestic work, while others could do some tasks or very few. Some could have difficulty reading or using the telephone. Therefore some of the informants had to take full responsibility for everything, such as finances and housework. For those informants who had a job to perform, anxiety for the spouse or the parent could make them mentally worn-out. They could not relax when at work. Some of the informants had earlier traveled a lot, for example abroad. Such opportunities were now reduced. Some had had terrible experiences of traveling with their spouses, but another still found such travel possible to manage.

It is a tough message and a tough diagnosis to get, and, as many say, it is hard to lose the spouse instantly. But it is very tough as well to lose the spouse day by day during a period of for example 10 years. This gradual loss is very tough.

Another challenge to manage for some of the informants was their spouses' or parents' forgetfulness, which could lead to forgetting to eat, not remembering where things were put or forgetting what to do. It was experienced as very tiresome to explain and repeat things all the time. One informant expressed that she needed to have some days free, but after a trip, she found that her husband had eaten very little. Another informant had decided not to be upset about her husband's forgetfulness, but found this almost impossible. Sometimes they allowed themselves to show their frustration, due to their stressful situation. One informant

Table 2 Examples of codes, sub-categories, categories, and a theme from content analysis of the two focus group interviews

\begin{tabular}{|c|c|c|c|c|}
\hline Theme & \multicolumn{4}{|c|}{ Contentment with adapted activities and group meetings provided with a person-centered approach } \\
\hline Categories & \multicolumn{2}{|c|}{ A break in the everyday } & \multicolumn{2}{|c|}{ Being attended and cared about } \\
\hline Sub-categories & $\begin{array}{l}\text { Need for } \\
\text { relief }\end{array}$ & Meaningful activities & Being confirmed & $\begin{array}{l}\text { Sharing experiences and } \\
\text { getting advice and help }\end{array}$ \\
\hline \multirow[t]{4}{*}{ Examples of codes } & Tough disease & To choose activities & Being seen & Being in the same situation \\
\hline & Responsibility & Positive experiences & Feeling safe & To ask questions \\
\hline & Anxiety & To get friends & Fantastic personnel & Reduced network \\
\hline & Forgetfulness & Personnel are following up & Taking care of & \\
\hline
\end{tabular}


tried to explain her problematic situation concerning her husband, and her answer was that the dementia disease could get worse. However, it was also experienced that to repeat things many times could be positive for the memory of the dementia sufferer. One informant had learned to tackle repeating questions by being calm and just answering.

There are many things that have to be explained many times.

He asks about the same thing many times, but I experience

it as most tiresome to search for things that he has put in an unusual place.

Another difficulty to handle was how much it was possible to expect the dementia sufferers to take an active part in the housework. Someone said they had to do things they wanted. Another next of kin said that for those who did not take their own initiative, it was necessary to ask them to do concrete tasks. However, several of the informants had realized that they had to take things day by day and tried not to think about the eventual worsening of the disease. The future was frightening. To take things day by day was experienced as a way to perceive the best possible quality of life, because both the informant and the spouse or parent, had to do their very best in the current situation. However, one informant was very worried for the future - indeed was terrified and could not stop thinking about an obvious worsening of the dementia symptoms.

You have to take day by day, and not think on the gradual worsening.

I do not manage to think on to take day by day. I am scared to death ... afraid for the future.

Another perceived challenge for some of the informants was that they felt isolated, because they could not leave their spouses alone, or their acquaintances had become limited. Some dementia sufferers showed clearly that they did not want guests in their homes. At the same time, if dementia sufferers were invited to the homes of others, they wanted to go back to their own home immediately. This was explained by the informants as a fear of being together with others, due to the fact that they were not able to handle the situation. It was also experienced that this difficulty was applicable in meeting many unknown persons, while meeting well-known persons was manageable. Someone was lucky to have relatives or a neighbor whom they could invite, or whose home they could visit. However, the perceived isolation could also include that some of the children had chosen to have reduced contact with the parent as a result of fear of facing the disease. To be forced to sell the car in order to hinder the spouse's driving could also be experienced as isolation.
We can visit others, but after half an hour he wants to go home again. The easiest is not to invite someone. It is very nice when someone is visiting us, but after half an hour he [the spouse] shows with the whole body that the guest has to go.

The dementia sufferers' opportunity to go to and use the activity center was acknowledged and appreciated by all of the informants. All of them had only positive experiences, and they expressed their expectation that this opportunity should continue. It provided the informants with a wanted relief. A desire to be alone in the house or to visit friends could be possible to realize. Those who were employed and had work duties to perform found it very satisfying that their spouses or parents were not alone at home. This could give a feeling of enthusiasm for the job, a good conscience, and a feeling of freedom when at the workplace. Someone had a desire that the activity center could also be open during an afternoon or an evening in the week. This could offer the possibility to be free an evening in the week.

Now I have a better conscience when I am going to job, because I know he is looked after ... I was very tired but now I am happier ... I am so happy to have my job to go to ... it is a pleasure to be a little free.

\section{Meaningful activities}

All the informants found the activities in the center very important and meaningful for their spouses or parents. The dementia sufferers got a new day. Some of them were not interested in the center when they were informed about it. However, after visiting the center, they were very satisfied with the arrangement and used it regularly. The frequency of their use could vary. Several used the center two or three times per week. Some preferred not to always go to the center, but if they were missed, the personnel phoned and asked for them. This was especially experienced by the informants as very positive because it resulted in visits to the center, and informants noted that their next of kin went home again as a new person.

He was not interested and he did not like it [the activity center] ... We agreed that he should try it once and he came home as a new man. He was very satisfied. He was so happy. He enjoyed himself. He met very nice people. Everyone was fantastic and he got a new day.

The visits at the activity center gave the day a framework for the dementia sufferers that provided safety both for themselves and the informants. The offered activities in the 
center were found to be comprehensive and balanced, and all dementia sufferers could find and choose activities that were convenient for them with respect to their needs, interests, and conditions; they felt part of a fellowship. Popular activities were to sing together and to participate in excursions. However, the most popular activities were bowling and walking in nature or in the city. Such exercises were activating and the bowling activity was also found to provide increased vigor and skills. To participate in a bowling competition was perceived as very amusing in addition to the possibility of being active. When someone won, there was jubilation in the bowling hall.

I think they had found a very good balance between a quiet open and a fixed arrangement ... They can come and go and they can take their own decisions if they will participate or not. It is not locked. Nevertheless, they feel that they are a part of a fellowship.

All of the informants reported positive changes in their spouses or parents as a result of the participation in different activities with the personnel and the volunteers at the center. They became more attentive. They were happy, engaged, showed enthusiasm, and had much to talk about when coming home. One informant had noted that apathy was prevented in her husband. Another informant described that her husband showed increased self-efficacy. Moreover, a person who earlier had been isolated had found new friends and had less dementia symptoms, which was assumed to be the result of participating in the activities. Someone had increased interest in being fresh and proper and was eager to take a shower. None of the informants had recognized unrestrained behavior in relation to their relatives' visits to the center.

She has considerably less dementia symptoms. She can take care of herself ... She was diagnosed ... She got medicines ... But I think it has been very stable, no negative changes, almost the opposite and it can just be due to the center ... When we see each other, it is always a theme what she has done at the center. It has been a fantastic difference [before and after the beginning at the center].

It was clearly expressed by all informants that they thought their spouses or parents felt included in the fellowship at the center, because all persons with dementia were in the same situation and could participate in the activities on the same premises. It was especially emphasized as an advantage that the different activities appeared on the same day week after week. Likewise, it was positively acknowledged that the activities were scheduled in a written folder. This made the days predictable for both informants and their next of kin.

The most important with the center is that they [the dementia sufferers] are together with other people in the same situation, otherwise they should felt themselves as being outside.

\section{Being attended and cared about} Being confirmed

All those visiting the activity center felt that they were welcome, whether it was the first time or on daily visits, because the door was always open. All of the informants remembered the first meeting with the personnel as very positive. They expressed that they always felt that they were given attention by the personnel and the volunteers when they arrived at the center. The personnel see everybody and they show a genuine interest and skill for their work. It was also experienced very positively that the personnel were always together with the dementia sufferers.

You feel yourself welcome and the door is open for everyone ... At once they hear that someone is going in the stairs, one of them [the personnel] is meeting and acknowledges that is very nice that you are coming.

The attentiveness and thoughtfulness of the personnel, and their fantastic personalities meant that the informants could not find any potential for improvement in the arrangements in the activity center. Therefore, the informants felt safe there. This safety was based on the belief that their next of kin were looked after in a very good way and that the dementia sufferers enjoyed themselves at the activity center. To have this contact with the center also provided safety for the future, because they were sure to be looked after and be given help if they needed it later on.

You have no home nursing, because you have not the need yet, thereby nobody has contact with you ... Therefore, it is very good to have this safety to contact the personnel at the center.

\section{Sharing experiences and getting advice and help}

One day each week, the informants had the opportunity to participate in group meetings at the center. Because these group meetings were in the daytime, however, it was not suitable for those who were active workers. However, those who participated in the meetings expressed these to be very valuable, because of the possibility of sharing experiences with those who were in the same situation. A topic that had 
been discussed was that other people could have difficulties in understanding the situation of a next of kin to a dementia sufferer. It could be difficult to understand because they had no such experience. The informants had also found that some people did not want to have contact with them anymore. Some informants had experienced that the dementia disease could be difficult for their own children to handle. By sharing these experiences, they were not alone in their situation anymore. In addition to the possibility of sharing experiences, they felt that they had support and help from the personnel. Furthermore, to meet other persons with similar experiences was acknowledged so positively that some informants desired that the group should also meet outside the center. The informants also felt that they could ask and get advice and help from the personnel regarding practical challenges, for example, about aids and assistive devices that could facilitate everyday life for their relatives. They wanted, for example, some aids for helping to use the telephone and television in a better way. The personnel could obtain information about aids and be helpful in the search for appropriate assistive devices.

I have found it very positive to share experiences and you do not feel alone ... It is the fine thing with the center that you are not alone and you have someone you can ask.

\section{Contentment with adapted activities and group meetings provided with a person-centered approach}

Through an interpretation of the categories "a break in the everyday" and "being attended and cared about," with the two sets of sub-categories "need of relief" and "meaningful activities," and "being confirmed" and "sharing experiences and getting advice and help," the overall theme "contentment with adapted activities and group meetings provided with a person-centered approach" emerged. Participation by dementia sufferers in the physical and social activities at the center led to an increased level of well-being, for both themselves and their next of kin. The dementia sufferers' use of the center provided opportunities for the next of kin to participate in group meetings that were supportive. For the dementia sufferers to be confirmed as the people they were, and to be included in a fellowship, gave them the value of being whole human beings. To be surrounded by personnel with high competence and a person-centered attitude was crucial for activities to be perceived as meaningful for the dementia sufferers, and enabled the next of kin themselves to feel a sense of support in a difficult life situation.

\section{Discussion}

The aim of this study was to elucidate experiences by next of kin to home-dwelling people in an early stage of dementia who had an opportunity to participate in organized physical and social activities. The findings showed that the informants, as next of kin to dementia sufferers in an early stage of the disease, experienced life as a burden. This was the case because of, for example, feelings of isolation and worries about the future, which is also a known result from other studies. ${ }^{1,3,4}$ The findings highlight that next of kin to dementia sufferers need relief ${ }^{6}$ and support. ${ }^{4}$ For the informants in the present study, it was possible to get relief and support as a result of their spouses' or parents' participation in organized activities with access to personnel with a specific competence in caring for people with dementia. This result can be compared to the study by Lilly et $\mathrm{al}^{6}$ who found that provision of health care services to persons with dementia also had an impact on the health and wellbeing of their next of kin. The present study shows the importance of municipalities organizing activities for home-dwelling people with dementia and, thereby, providing a winning situation for the next of kin.

The informants found that participation in meaningful activities had a positive impact on the wellbeing of persons with dementia. Corresponding findings are also present in other studies ${ }^{9,10}$ among people with dementia. In the study by Cedervall and Åberg, ${ }^{15}$ one next of kin found physical activity to be very positive because the activity provided benefits such as peace and quiet, and pleasure for the person with dementia. Furthermore, the present study revealed that it was positive that the activities gave the day a structure and that the different activities appeared on the same day, week after week, which made the days predictable. This shows that it is important for a person with dementia to have routines in everyday life. The studies by Berg et $\mathrm{al}^{16}$ and Cedervall and Åberg ${ }^{15}$ support the idea that routines give structure to the day and that the person with dementia usually prefers the same routines day after day. ${ }^{15}$

That the center could offer many different activities and that it was an opportunity for the persons with dementia to choose and find suitable activities was acknowledged by the informants as very positive in the present study. Aggarwal et $\mathrm{al}^{4}$ reported similar findings, ie, that people with dementia who attended a day care center appreciated the choice of different activities. Moreover, they found more positive comments about daycare centers than residential homes. ${ }^{4}$ Because increased numbers of people with dementia are expected in the years to come, ${ }^{17}$ and because Norway has the political goal that people should live as long as possible 
in their own homes, ${ }^{7}$ a political assignment should be that activity centers are a real possibility for home-dwelling people with dementia in order to enhance their wellbeing.

To be included in a fellowship was important for the dementia sufferers, but also for the informants. They all were given attention and became confirmed by the personnel. To have this contact with highly skilled personnel provided safety and opportunities to get advice and help for the informants and, moreover, the persons with dementia were valued as whole human beings. In the study by Steeman et al, ${ }^{18}$ it was revealed that being valued was important for older people with dementia. It provided experiences of self-worth and being valuable to others, but also of being loved and cared for by others. Brataas et $\mathrm{al}^{10}$ found that people with mild dementia who participated in social and cultural activities, once each week, could maintain their identity and cultural values. They also developed social relationships and got a feeling of belonging to a group. In the present study, there was an example of a person who obtained new friends when participating in the physical and social activities in the center. It was also experienced by the informants that their relatives were happy, engaged and had much to tell about at home. Brataas et $\mathrm{al}^{9}$ also found that dementia sufferers had a lot to tell after participating in social and cultural activities.

However, Lilly et $\mathrm{al}^{6}$ found that, regarding health care provision, constant staff turnover is negative for dementia sufferers. Berg et $\mathrm{al}^{16}$ highlighted that supportive long-term contacts were important for people with dementia in order to help them gain a personal understanding of their own disease. In the present study, the dementia sufferers met the same personnel each time they attended the center. This continuity can be of importance for the positive experiences of attention the next of kin and the dementia sufferers experienced. In addition, the personnel met the persons with a person-centered attitude. According to McCormack et $\mathrm{al}^{19}$ person-centeredness has an element of a high-quality relationship between the caregiver and the patient or client, and the caregiver can provide a meaningful, engaged relationship with patients or clients. The present findings show a strong indication that such relationships were established with the dementia sufferers and the next of kin. Sjögren et $\mathrm{al}^{20}$ have shown, in a study in dementia care units, a relationship between person-centered care and the dementia sufferers' ability to perform daily activities. The residents gained, for example, a higher ability to eat, drink, and manage toileting, and a higher quality of life compared to other residents in units with a lower level of person-centered care. An explanation for the findings reported by Sjögren et $\mathrm{al}^{20}$ could be that the personnel knew the residents very well and could support them in completing these activities. In a systematic review study, Olsson et $\mathrm{al}^{21}$ found that person-centered care may lead to significant improvements in the patients. However, there is a need for more studies. ${ }^{20,21}$

\section{Methodological considerations}

It is a weakness of the study that only ten informants participated in the focus group interviews. It was desirable that more next of kin were included. However, the two focus group interviews provided rich data, which revealed entirely positive experiences of the informants. A larger number of informants would most likely have been able to provide more varied findings.

Trustworthy findings are the strength of qualitative studies. A way to ensure trustworthiness of the findings is to follow the steps of the analysis, ${ }^{12}$ which has been done with care in the present study. Furthermore, using quotes is a way to show the reader how well the data cover the categories, ie, the credibility of the findings. ${ }^{12}$ Trustworthiness also includes how the findings can be transferred to other groups. ${ }^{12}$ As the findings correspond well with other studies about people with dementia and their next of kin, ${ }^{1,4,15}$ it is assumed that the findings are transferable, to a high degree, to similar contexts, ie, other activity centers with physical and social activities for people with dementia in an early stage.

In the present study, a latent analysis was used to interpret the underlying content in the categories in the manifest content analysis. ${ }^{12}$ The pre-understanding used in this interpretation was the authors' knowledge and experience of being nurses with experience of caring for and about older people and people with dementia. In addition, two of the authors have experience of care organizations for people with dementia.

\section{Conclusion}

The conclusions of this study are that an activity center, for people with dementia in an early stage, offering adapted physical and social activities led by highly qualified personnel with competence in caring for and about people with dementia, can provide needed relief and support to the next of kin, and meaningful activities to the dementia sufferers. However, it is crucial that the personnel provide personcentered care and are able to meet the needs of the dementia sufferers and their next of kin in order to give them a new everyday life.

Because of the expected increase of dementia sufferers in years to come, and the fact that centers with specially adapted physical and social activities can enhance the wellbeing 
of these people, politicians have a responsibility to offer such facilities. More studies are needed to elaborate on the associations between organized adapted physical and social activities and enhanced wellbeing in home-dwelling people with dementia, from the perspective of the next of kin and the people with dementia.

\section{Acknowledgments}

The study was financed by the Faculty of Health and Sport Sciences, University of Agder, Norway. We express our gratitude to the participants.

\section{Disclosure}

The authors report no conflicts of interest in this work.

\section{References}

1. Samuelsson AM, Annerstedt L, Elmståhl S, Samuelsson SM, Grafström M. Burden of responsibility experienced by family caregivers of elderly dementia sufferers: analyses of strain, feeling and coping strategies. Scand J Caring Sci. 2001;15(1):25-33.

2. Connell CM, Roberts JS, McLaughlin SJ, Carpenter BD. Black and white adult family members' attitudes toward a dementia diagnosis. J Am Geriatr Soc. 2009;57(9):1562-1568.

3. Beard RL, Neary TM. Making sense of nonsense: experiences of mild cognitive impairment. Sociol Health Illn. 2013;35(1):130-146.

4. Aggarwal N, Vass AA, Minardi HA, Ward R, Garfield C, Cybyk B. People with dementia and their relatives: personal experiences of Alzheimer's and the provision of care. $J$ Psychiatr Ment Health Nurs. 2003;10(2):187-197.

5. Teel CS, Carson P. Family experiences in the journey through dementia diagnoses and care. J Fam Nurs. 2003;9(1):38-58.

6. Lilly MB, Robinson CA, Holtzman S, Bottorff JL. Can we move beyond burden and burnout to support the health and wellness of caregivers to persons with dementia? Evidence from British Columbia, Canada. Health Soc Care Community. 2012;20(1):103-112.

7. Norwegian Ministry of Health and Care Services. Report No 25 (2005-2006) to the Storting Chapter 1, 2 and 3. Long Term Care - Future Challenges. Oslo: Ministry of Health and Care Services.
8. Donath CD, Grässel E, Grossfeld-Schmitz M, et al. Effects of general practitioner training and family support services on the care of home-dwelling dementia patients - Results of a controlled cluster-randomized study. BMC Health Serv Res. 2010;10:314.

9. Eggermont LHP, Scherder EJA. Physical activity and behaviour in dementia. Dementia. 2006;5(3):411-428.

10. Brataas HV, Bjugan H, Wille T, Hellzen O. Experiences of day care and collaboration among people with mild dementia. J Clin Nurs. 2010;19(19-20):2839-2848.

11. Polit DF, Beck CT. Essentials of Nursing Research - Appraising Evidence for Nursing Practice. London: Wolters Kluwer/Lippincott Williams \& Wilkins; 2010.

12. Graneheim UH, Lundman B. Qualitative content analysis in nursing research: concepts, procedures and measures to achieve trustworthiness. Nurse Educ Today. 2004;24(2):105-112.

13. WMA Declaration of Helsinki. Ethical principles for Medical Research Involving Human Subjects. Seoul: WMA; 2008. Available from http:// www.wma.net/en/30publications/10policies/b3/index.html. Accessed March 15, 2013.

14. Beauchamp TL, Childress JF. Principles of Biomedical Ethics, 6th ed. Oxford: Oxford University Press; 2009.

15. Cedervall Y, Åberg AC. Physical activity and implications on wellbeing in mild Alzheimer's disease: A qualitative case study on two men with dementia and their spouses. Physiother Theory and Pract. 2010; 26(4):226-239.

16. Berg AI, Wallin A, Nordlund A, Johansson B. Living with a stable MCI: Experiences among 17 individuals evaluated at a memory clinic. Aging Ment Health. 2013;17(3):293-299.

17. Ferri CP, Pronce N, Broday H, et al. Global prevalence of dementia: a Delphi consensus study. Lancet. 2005;366:2112-2117.

18. Steeman E, Godderis J, Grypdonck M, de Bal N, Dierckx de Casterlé B. Living with dementia from the perspective of older people: is it a positive story? Aging Ment Health. 2007;11(2):119-130.

19. McCormack B, Karlsson B, Dewing J, Lerdal A. Exploring personcentredness: a qualitative meta-synthesis of four studies. Scand J Caring Sci. 2010;24(3):620-634.

20. Sjögren K, Lindkvist M, Sandman PO, Zingmark K, Edvardsson D. Person-centredness and its association with resident well-being in dementia care units. $J A d v$ Nurs. January 21, 2013. [Epub ahead of print.]

21. Olsson LE, Jakobsson Ung E, Swedberg K, Ekman I. Efficacy of personcentred care as an intervention in controlled trials - a systematic review. J Clin Nurs. 2013;22:(3-4):456-465.
Psychology Research and Behavior Management

\section{Publish your work in this journal}

Psychology Research and Behavior Management is an international, peerreviewed, open access journal focusing on the science of psychology and its application in behavior management to develop improved outcomes in the clinical, educational, sports and business arenas. Specific topics covered include: Neuroscience, memory \& decision making; Behavior

\section{Dovepress}

modification \& management; Clinical applications; Business \& sports performance management; Social and developmental studies; Animal studies. The manuscript management system is completely online and includes a quick and fair peer-review system. Visit http://www.dovepress. com/testimonials.php to read real quotes from published authors. 